\title{
E-Government in a New Technological Ecosystem
}

\author{
Marian STOICA ${ }^{1}$, Bogdan GHILIC-MICU ${ }^{1}$, Marinela MIRCEA ${ }^{1}$, Panagiotis SINIOROS $^{2}$ \\ ${ }^{1}$ Bucharest University of Economic Studies, Romania, \\ ${ }^{2}$ Technological Educational Institute of Piraeus Athens, Greece \\ marians@ase.ro, ghilic@ase.ro, mmircea@ase.ro, pasin@teipir.gr
}

The growing communication needs demanded by a constantly changing society significantly stimulate the current information and communications technology industry. Consequently, we can see an exponential development of ICT which, corroborated in the IoT context with the new paradigms in the field of software development (cloud computing, fog computing, blockchain, etc.), and in the nanotechnology industry draws the boundaries of a new technological ecosystem. As any ecosystem presupposes the existence of a food chain, and in the case of the new technological ecosystem we discover the producers and decomposers. They can be assimilated to technological tools and primary resources on the one hand (IoT, internet, water, air, electricity, etc.), respectively to individuals and communities on the other hand. This is the overall image or background over which aggressive digital solutions are being developed, in various fields, which respond to increasingly specialized, more concrete needs: education, culture, socialization, sports, transport, health, ..., administration, government. In this paper we will present the main aspects of governance in the new technological ecosystem, emphasizing the aspects of e-government and democracy, voting and e-legislation contained in what we generically call e-government.

Keywords: e-government, e-law, e-voting, e-democracy, ITC, cloud, blockchain, web 2.0

DOI: $10.24818 /$ issn14531305/24.3.2020.01

\section{Introduction to E-Government}

The term „electronic government” involves using electronic communication technologies to improve democratic processes in a country. This involves four main components: interaction between government and citizen (G2C), which aims to modernize public services provided to citizens; interaction between government and business environment (G2B); interaction between government and public servants (G2E), which involves using electronic means for communications with government employees or applications that facilitate fulfilment of tasks; interaction between government institutions (G2G) - figure 1. Initially, electronic government appeared from the desire to provide citizens with public services through the means of information and communications technologies (ICT), giving those better opportunities for direct access to government. This supports more active participation of citizens to making public policy decisions, allowing them a greater influence. A better electronic government brings many benefits: government gains increased trust from citizens, there is a more attractive government, evolution towards a more evolved digital society, which may lead to a significant economic progress. 


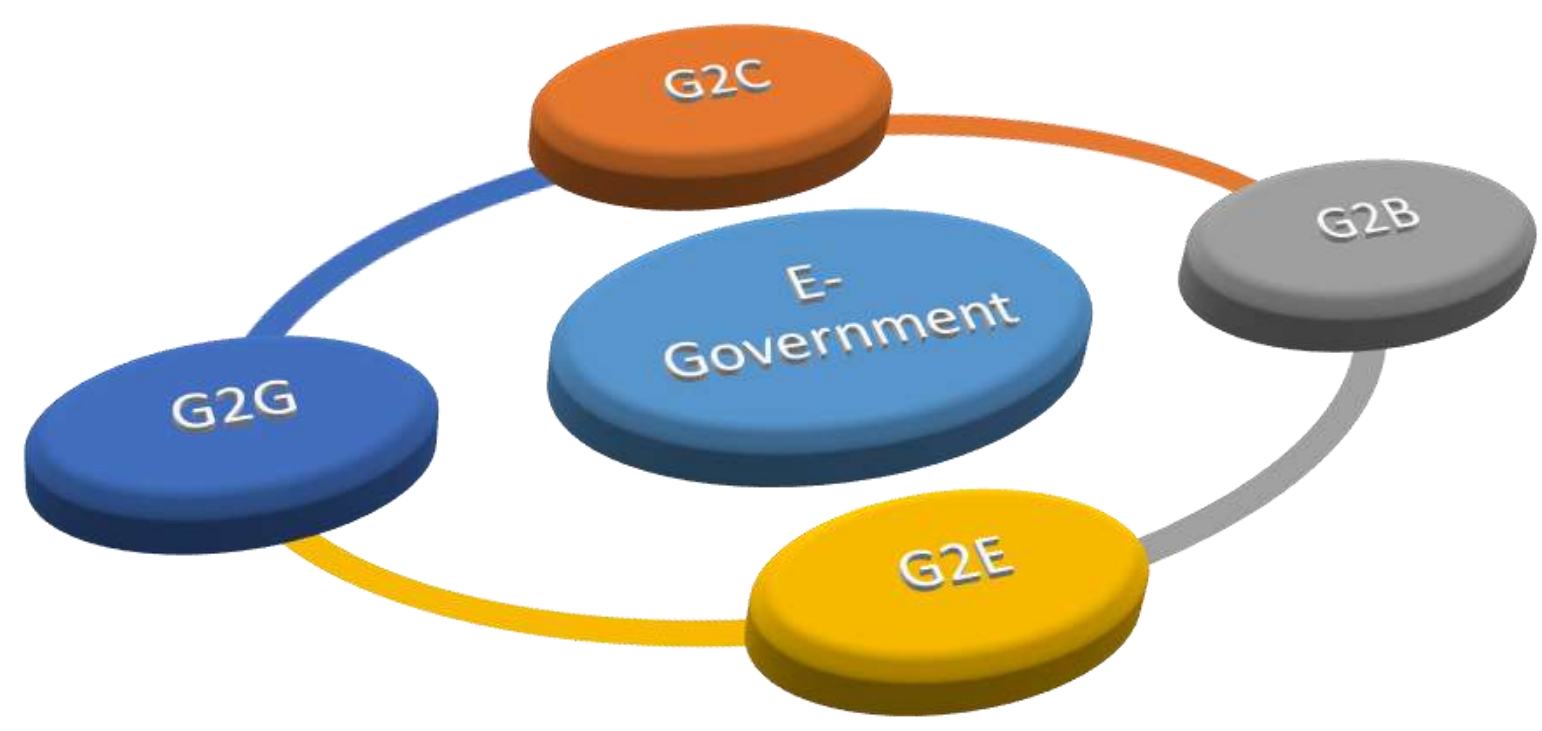

Fig. 1. Classical pylons of electronic government

The need to implement new government technologies is more and more obvious these days. There is a desire to call on various instruments like socializing sites to involve more individuals in the political life, to mobilize voters, increase citizen participation to political life, improve public services and favor innovation and economic growth. Thus, governments are forced to implement new emerging technologies, most favored being currently social media and cloud computing. Web 2.0 technologies designate those websites that allow users to interact and share information online, faster and easier, through social media, blogging and web-based community, such sites being more and more dynamical and interconnected. The main features of web 2.0 technologies are: providing simple applications that solve specific problems and that may be accessed from anywhere, anytime, data can be easily shared and collaboration between individuals is encouraged, offering new ways for interaction and collaboration between individuals as well as sharing information with large groups of people.

As for the government, web 2.0 technologies have a significant impact, a long list of applications being already in use. The nature of this impact is characterized mainly by the more active role of users, the term "user" defining both public servants and citizens. In the last decade digital government environments have evolved a lot, increasing the participation, transparency and integration. The use of web 2.0 technologies has made possible the move from serviceoriented architecture (SOA) to web-based architecture (WOASs). Web 2.0 technologies lead to a more active government interaction with the public, through various mechanisms like live chats, blogs, web comment forms for feedback from citizens, social media becoming a central component of government strategies.

Cloud computing (CC) is a distributed kit of computing services, applications, storage and data access, where the user does not have to know the location and physical configuration of the systems providing these services. For the government, $\mathrm{CC}$ is the best choice for storing, updating and protecting data, providing many benefits, main ones being flexibility, cost decrease, collaboration. Regarding the flexibility, $\mathrm{CC}$ is more advantageous than traditional technological infrastructures, eliminating the problems that arise due to limited resources, purchase and maintenance of servers and hardware equipment, data protection. Organizations that decide to use cloud services may chose various service models like SaaS, PaaS and IaaS and may implement software in public, private or hybrid cloud, depending on security 
requirements and budget. Storage space is no longer an impediment, in the public version being virtually unlimited, while in the private version it can be extended fast and easy.

From the cost perspective, cloud use considerably diminishes IT costs of an organization, reducing the amount paid for equipment and infrastructure. It brings the possibility to access larger computation resources without purchasing and maintaining servers, which involves extra costs for electricity, storage and qualified personnel. Additionally, there is no need to pay for various licenses and taxes for software. CC helps the collaboration between government agencies, allowing sharing of various documents from anywhere in the world, the only condition being a connection to internet. $\mathrm{CC}$ paradigm provides support for the development of electronic services in an environment easy to use, with unlimited access, direct communication and real time information. The security aspect of these services must receive a special attention. There are a few main features of e-services in a digital world. One of them is scalability, indicating the ability to manage larger and larger amounts of work tasks. Cloud systems provide the best support for hosting electronic services, providing solutions for the usual problems. Thus, technologies that support and help evolve CC are needed in order to successfully apply the electronic government, one of the important manifestations of informational society involving state institutions, public and private organizations and, most important, the citizens which are transformed into e-citizens, involved into all aspects of life: political, social, economic and cultural.

\section{E-Democracy}

E-democracy, also known as electronic democracy, means the use c ICT by democratic political actors in the governing and political processes of local, national and/or international community. "Political actors" means governments, elected officials, mass-media, political organizations and, most important, the citizens. In a broader sense, electronic democracy means giving the citizens the opportunity for a more important and active participation to the governing process, through internet, mobile communications and other technologies. In this sense, most e-democracy theoreticians agree that with this concept and introducing new forms of online communication, the traditional barriers for involving the citizen int the liberal-democratic policies can easily be overcome [1]: lack of time, community decline and lack of deliberation opportunity. Citizen participation is necessary to build democracy, being a crucial element for controlling the leaders, a better transmission of preferences, attenuation of conflicts and reducing the costs of making political decisions. Additionally, participation promotes a type of citizen that has a better interest in being informed about the political life, cooperating with others and is more respectful towards the others, thus consolidating social links between people and favoring inter-cultural understanding.

Citizens' opinions, suggestions and critics can determine the type of democracy a country can have and its quality. Under these circumstances, citizen participation becomes a very important issue, with significant implications on the entire society. For example, the latest elections in the world (not only Romania), people under 35 years showed a lack of political interest. This is one reason why electronic democracy is suggested as a possible method to raise voting participation and gaining political knowledge. Even more, the significant changes induced by the health crisis push in the same direction.

The first signs of electronic democracy appeared in the ' $60 \mathrm{~s}$, when a generation of political theoreticians, including important names like Benjamin R. Barber, Crawford Brough Macpherson or the younger at the time Carole Pateman established an agenda for participative democracy that endured until $21^{\text {st }}$ century [5]. The concept of community, one of the most important of elements of electronic democracy manifested in 1980, when specialists in political sciences and sociologists like Robert N. Bellah, for 
example, have risen up against the intensification of individualism in US society and requested new community ethics.

The one to consolidate the basis of edemocracy was Jürgen Habermas, through his concept of public sphere: "an autonomous idealized communication sphere, where citizens may freely get involved in motivated debates outside the controlled influence of the state and mass-media corporations". Jürgen Habermas is a German philosopher and sociologist that became known mostly though his works on social philosophy. He was associated with Frankfurt School and conceived the theory of communicative activity where internet is a uniquely adequate mean of communication able to provide support for many areas of political debates, which are relatively spontaneous, flexible and self-governed. Thus, in the " 70 s emerged for the first time the so-called "community networks" which will be integrated in many liberal democracies starting with the '90s, when costs for software, hardware and network equipment started to lower. As a definition, "community networks" are publicprivate schemes that feature three main components: a high-speed network provided freely or subsidized to households, a sort of community technological center and focus on creating local community related content. Thus, they rely on the idea that by providing citizens with the opportunity to shape the online information regarding the local neighborhood, virtual communities may improve the geographical communities by creating new social bonds and mutual trust, the ingredients of social capital.

At the dawn of $21^{\text {st }}$ century there was an attempt to connect the online networks to the formal political processes. Central and local government agencies started to experiment with online policy discussions and consultations with citizens. Various democratic projects emerged, all centered on the use of internet. They generally followed two main directions: consultative and deliberative.

Consultative approaches highlight the communications of citizens' opinion to the government. It starts from the idea that information is an important resource that may be used to ensure a better policy and administration. The best such example is the federal USA government program for adoption of electronic rules, which allows the citizens to comment on the department and agency rules as they are being developed.

Deliberative or discursive democracy is a form of democracy where deliberation is centered on making decisions and is based on the rule of majority. This differs from traditional democracy because authentic deliberation, not only voting is the main source of legitimacy for a law. Thus, in order for a decision to be legitimate, it must be preceded by an authentic deliberation, simple aggregation of voting preferences is not enough. It may be made by decision factors both in representative democracies as well as in direct democracies. As a consequence, edemocracy must be oriented on the following priorities (figure 2):

$\checkmark$ Stimulation of citizen involvement in local government;

$\checkmark$ Empowering local citizen associations;

$\checkmark$ Support for easement of digital division;

$\checkmark$ Ensuring instruments for the citizens to enable participation in decision processes on local level, where they are directly concerned. 


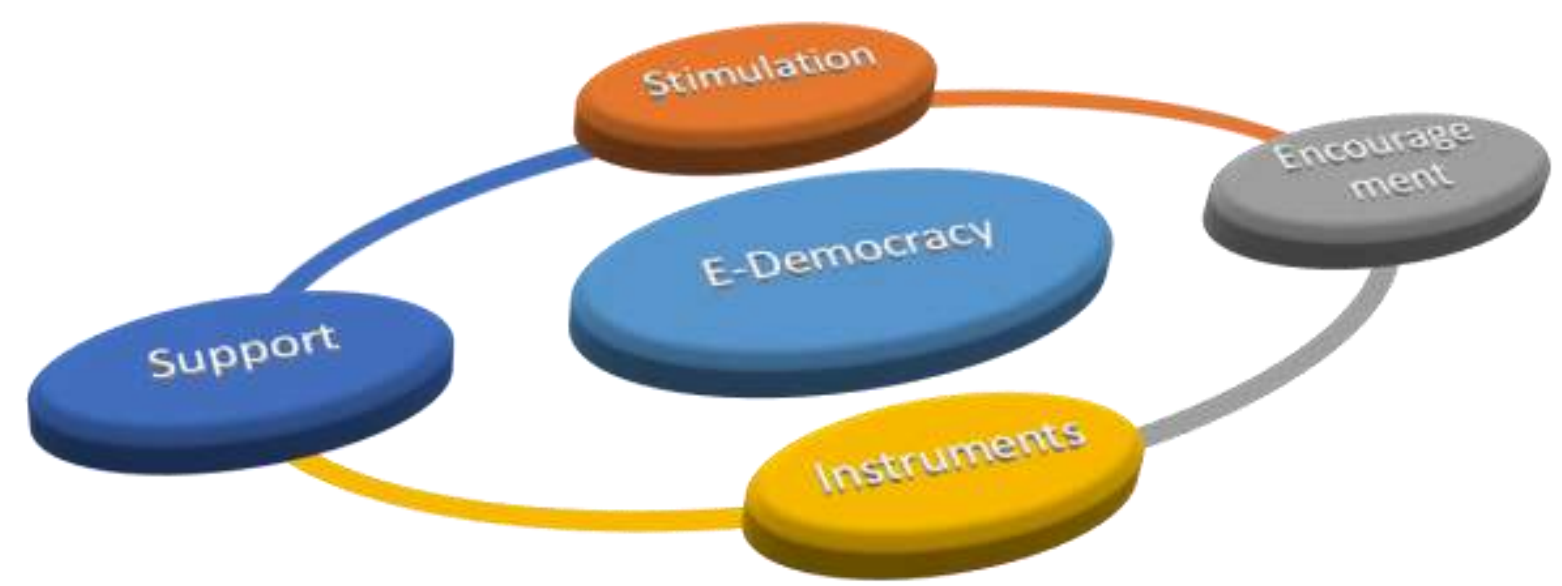

Fig. 2. E-democracy priorities

E-democracy seeks to achieve several objectives, among which providing the individuals with rights, expanding and improving the democracy and digital inclusion. Liberty and human development are encouraged through spreading of free information though internet. Any individual has the possibility to know his rights, respectively free speech, access to religion, government responsibility, and the right to knowledge and understanding, aspects that support the democracy. The internet has many features that allow for it to be considered a democratic environment though which participants to a democracy may keep up to date with all that happens in their government, allowing everyone's voice to be heard. It is a very flexible participative environment, with low costs and readily available for the public. The innate usability of search engines leads to increased involvement of citizens in political problems. Mass communication through news groups or social networks allow individuals to gain or publish information related to government. This collective decision and problem solving provides more power to citizens and helps politicians make better decisions. In turn, this creates a more productive society that can solve problems easier and more efficient. One such example is the USA, where politics became dependent on internet, which is the main source of information for most citizens. The feedback and the advices from the population constitutes a large part of a US politician's activity, this increased ability to communicate with the public allowing a more efficient functioning of the government. The entire world, including Europe is accelerating in this direction of e-democracy.

Digital inclusion is essential for citizen participation on formulation of public policies, for a healthy digital democracy, through equal participation of all society sections to democracy, no matter the level of citizen income, education, gender, religion, color and ethnicity. Any public policy formulated without including any society section will forever remain non-inclusive by nature and will go against the essence of democracy.

In order to implement e-democracy, a few prerequisites must be achieved, like: internet access, ensuring the security and protection of private life, government responsibility. Without internet access nothing is possible, this being the reason why less developed countries are lagging behind in implementing e-democracy. One possible solution, used a lot in African countries is the creation of public libraries that provide citizens with access to internet and government services.

In order to entice people to get involved in online consultations and debates, the government must answer citizens and actively prove there is a relation between individual involvement and political outcome. Also, it is important for the people to be able to get involved at a time and place of their choosing, when their opinion makes a difference. 
Citizens have the right to efficient public debate and moderation, consolidating the efficiency of existing legal rights to access public authority information. Correct and timely information for population is very important.

Regarding the security and protection of private life, the government must be able to guarantee the safety of online communication systems and ensure the confidentiality of communication. This is very important when talking about electronic voting or any other public service. A possible solution for security is the use of cloud computing for data storage. This technology provides better protection to personal information compared to current confidentiality practices. Cloud computing is the internet on-demand service that does not force the user to have his own technological infrastructure, thus saving money and benefiting from access to a large service network and a safe unlimited storage space. Large cloud providers may be able to use better security technologies than small companies and have better capacities for backup and incident response and recovery. There are still problems that can be generated by physical distance from the storage location (a reason from which fog computing paradigm emerged), the large number of clients, possible misuse of data (use for other purposes than intended or, due to low storage cost, storage of excessive amounts of data).

Some states are trying to create solutions to increase the security of cloud data. One such example is Canada, which created in 2014 the ISO/IEC 27018 standard for information technology, a practice code for protection of personal identifiable information in public clouds. This standard involves the creation of a base of security certificates that combine the technological power of the provider with a framework that ensures conformity: according to the contract, for which the compliance is verified through audits, the cloud client maintains control over his data and the provider cannot use them for any other purpose than defined by the client.

E-democracy starts to show a significant evolution, especially due to the emergence of web 2.0 technologies. The new information processing techniques, including Big Data Analytics and Semantic Web contribute to the development of future forms of electronic democracy. Currently, the e-democracy process is supported by technologies like electronic mail lists, peer-to-peer networks, collaboration software and applications (like GouvernEye, VoteSpotter, wikis, forums and blogs). Social sites like Facebook, WatsApp, LinkedIn, Google+, Twitter, Instagram, Pinterest, Befilo, Zoimas or Messenger play an increasingly important role in democratic deliberations. Supporters of electronic government see the government use of these networks as a mean to help leadership interact more with the public, the citizens.

E-democracy aims to contribute to the construction of direct democracy mechanisms in local communities, with the purpose of bringing the administration closer to the citizens (direct involvement of citizens in the process of public policy elaboration). Through the use of new participation means, the political debate is extended into the community. There are cases where electronic democracy cannot be efficiently used, especially for states with a high level of government censorship. Often government implement internet suppression during political processes. There are also many examples of states that have implemented various internet blockages in order to prevent the spreading of phone made video clips showing violent repression of protesters or another bad things.

Thus, even though e-democracy has sparkled many theoretical discussions, its main themes are more and more incorporated in practical policies. The use of ICT, like internet, cloud computing, web 2.0 technologies help create the mechanisms of direct democracy in local communities in order to bring the government closer to the citizens, the result being the direct contribution of population in policy making.

\section{E-Voting}

Electronic vote uses electronic devices to help the citizens manifest their choice or help the 
organizers count the votes. Depending on implementation, electronic voting may use stand-alone electronic voting machines (EVM) or computers connected to internet with various level of services, from transmission of results to actual online voting. The degree of automation may be limited to marking a physical paperback ballot or it may be a complete voting system, including actual voting, encoding, and transmission of the information to servers to tally the votes. The first implementation of electronic voting took place in Brazil in 1995, when electronic ballots were developed for use in 1996 municipal elections [2].

There are two types of technologies for electronic voting, quite different one from the other: electronic voting with physical oversight by representatives of government election authorities and remote electronic voting through internet, also called i-vote.

As time passed and internet penetrated the daily life, the voting process found a new form, called i-voting. This allows voters to manifest their choice from any device connected to internet, from anywhere, including from own home. Many have seen this as an opportunity to transform the democracy, allowing the citizens to directly participate to the decision-making process. Still, many countries have decided that internet is not safe enough for voting. Therefore, countries like Estonia, Switzerland and France have imposed restrictions on ivoting. Additionally, these countries consider that many personal computers are vulnerable to penetration by various types of malware which can launch attacks to block or replace legitimate votes, thus falsifying the entire voting process in an untraceable way. A third problem is the possibility of coercion against the voters and vote selling, which is easier to happen when voting takes place in an uncontrolled environment [3].

Due to vulnerability issues, most electronic voting takes place in secure spaces, using specialized machines. There are two types of electronic voting machines: direct recording machines and optical scanning machines. The machine records the voter's choice using a voting display with mechanical or electromechanical components that can be activated by the voter and data processing is done by a software. After the election process is over, the machine produces a table with the results (a copy is stored in its memory). The system may also provide a way to transmit the individual ballots or the final tally to a central location for consolidation and reporting purposes.

One vulnerability of these machines is the danger of computer viruses. For a virus to infect a machine, it must interact with another electronic device and this is why internet connection and wireless connection are usually forbidden. The fear that the machine does not record the votes as they were cast made the public demand that the machine also print a copy of the ballot, this feature being later added. Still, electronic recording machines were later replaced by optical scanning technology.

In some optical scanning systems (figure 3), the voter fills in a paper ballot and inserts it into an electronic scanning device. The invalid ballots are rejected allowing the voter to try again. This can lead to fewer canceled/invalid votes. Other optical scanning systems allow the user to compose the vote on the machine's screen. When the choice is made, the computer prints the ballot, the voter verifies it and inserts it into another device that records the vote.

An electronic voting system must be capable to successfully meet the specific requirements associated to security, accuracy, integrity, speed, confidentiality, accessibility and feasibility. Thus, among the most important benefits we can note the huge increase in ballot counting speed and personnel cost reduction. Additionally, the voters save time and money since they can vote from wherever they are. It also benefits citizens living abroad, in remote rural locations and persons with mobility disabilities. In conclusion, we may say that electronic voting can improve the image of a state and help promoting it. 


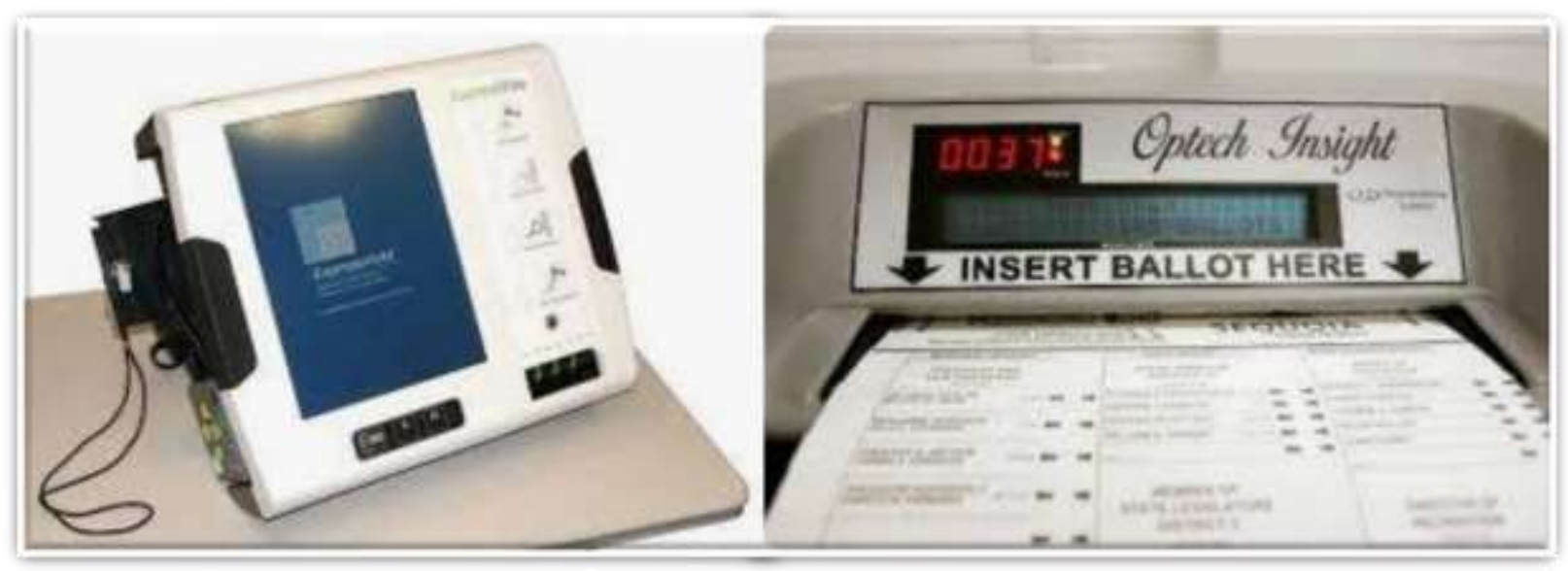

Fig. 3. Optical voting system (with ballot paper) [7]

The electoral system is an essential element of democracy and transferring it into an electronic service may be pretty difficult. Electronic voting is considered an important subject for the advancement of democracy in the world. If a safe and convenient electronic system can be developed, then it can be used more often to consult the citizens, through electronic means, regarding a large variety of decisions. An efficient analysis of various types of attacks, their goals and probability may help in the process of developing an electronic voting architecture that must be secure and trustworthy. An electronic voting system, even one accessible though internet, must take advantage of the new technologies to design, build and maintain it [4].

Cloud computing is used in various areas and one of them is electronic voting. There are various ways of voting, like traditional voting with open cloud, SMS voting, web voting.

Regarding the traditional voting with open cloud, it starts with manual verification of voter identity by an election official, crosschecking voter id with the voter database. The system relies on the working principle of direct recording electronic machine. An intelligent voting card is provided to the voter, with the additional advantage of preventing multiple votes. After casting his vote, the voter may review and confirm his choice.

SMS voting allows the user to transmit his choice regardless of the mobile network he uses. During the voting process he must pass a voice recognition test to demonstrate identity and avoid frauds. This system works only on Android phones.

Web voting system allows the voter to cast his choice through internet. Both Android phones and internet use the same backend database, so the voter has two options. This system has four stages: registration, authentication, actual voting (where the voter casts his choice and election authority encrypts the vote and sends it further) and tallying.

Blockchain protocol is an instrument to record and authenticate data, being transparent and distributed among users. Usually, the votes are saved, managed, tallied and verified by a central authority. Electronic voting powered by blockchain might empower the voters to perform these tasks themselves, allowing them to gain an accurate copy of a vote recording. Illegitimate votes cannot be added, because the voters will discover them. Such a system may diminish the power of central actors, the results being based on technology. Currently, blockchain experts debate a new generation of techno-democratic systems, and we can already see the emergence of virtual equivalents of national administrations based on blockchain (used for internal party elections in Estonia and Denmark in 2014 [6]).

Speaking of modern mass-media technologies of our time, web sites are an excellent way to transmit a large amount of information to voters, compared to traditional means of communication. More and more countries where internet access is widely available, political parties can greatly extend their ability 
to provide information by using electoral sites. Besides providing information, they can also be interactive. Users can complete online transactions like requesting voter registration or voting place choice. In the digital era, political parties may exploit the internet to stimulate political involvement, both online and offline. A good example is the national elections of 2013 in Italy, when all major parties had not only a web site with multimedia content, but were also active in web 2.0 applications, with official YouTube, Facebook and Twitter channels. Thus, political parties start to take advantage of the ICT opportunities, taking into consideration that internet has evolved a lot, increasing the exposure of electorate to political information. Thus, the electronic voting technology in any form or shape (be it punch cards, optical scanning, voting kiosks, internet transmission of ballots, mobile phone voting etc.) is an important step for passing to electronic government, a significant advancement for a state.

\section{Conclusions}

E-democracy, digital democracy or internet democracy incorporate $21^{\text {st }}$ century technology to promote democracy. This is an integral part of digital transformation of a nation, through intelligent use of digital instruments aiming to improve and transform existing government models and practices. ICT may significantly increase the transparency, sensibility and responsibility of governments and may provide the citizens with the opportunity to participate on political processes, which will lead to better outcomes for the society as a whole. Electronic vote uses the technology to make sure the citizens manifest their choice in a fast and safe manner. Depending in implementation it can use stand-alone machines, or internet connected computers.

Electronic voting technology may include punch cards, optical scanning systems or direct recording electronic systems. Also, it may allow transmission of ballots through phones, private computer networks or through internet. Governments that want to keep up with the digital age must provide their citizens with the most modern and efficient public services. This requires the move to electronic based government, based on new technologies like web 2.0 and cloud computing.

Web 2.0 technologies are considered the most recent phases in internet evolution and cannot be ignored by public sector. Online collaboration, social networks and various forms of community interaction have effects on political involvement, policy making, service providing and operational efficiency. Politicians gradually acknowledge the importance of communication channels, political blogs, YouTube clips, Facebook groups becoming an accepted part of the political landscape. Web 2.0 may direct the evolution of electronic government in new directions, not necessarily ones the public sector feels comfortable with.

We can safely assert that without adapting the leading and governing methods to the technological era, a country's the dream of prosperity and the ability to provide the best services to its citizens, by involving them in the political sphere, is hard, even next to impossible, to achieve.

\section{References}

[1] M. Burnester and E. Magkos, "Towards Secure and Practical E-Elections in the New Era", in Secure Electronic Voting (Dimitris Gritzalis Ed.), Springer International Publishing Switzerland 2003, ISBN 978-1-4613-4981-5 (eBook). Available:

http://link.springer.com/chapter/10.1007 \%2F978-1-4615-0239-5_5

[2] M. Stoica, B. Ghilic-Micu, E-Voting Solutions for Digital Democracy in Knowledge Society, Informatica Economică, vol. 20, no. 3/2016, pp. 55-65

[3] D.P. Moynihan, „Building Secure Elections: E-Voting, Security, and Systems Theory", Public Administration Review, volume 64, issue 5, pp. 515-528, September 2004

[4] C. Uscatu, E-voting. Techno-legal issues, The ICFAI University Press, Hyderabad, India, 2010, ISBN 978-81-314-2504-6 
[5] Benjamin R. Barber, Strong Democracy: Participatory Politics for a New Age, ISBN-13: 978-0520242333, ISBN-10: 0520242335, University of California Press, 1984, 2003, by The Regents of the University of California, printed in USA

[6] E. Marchesoni, July 2019, Blockchain EVoting Is Real: Where, How, When? https://irishtechnews.ie/blockchain-evoting-is-real-where-how-when/?

[7] Optical voting system with ballot paper, https://www.researchgate.net/figure/Opti cal-voting-system-with-ballotpaper_fig3_268657819

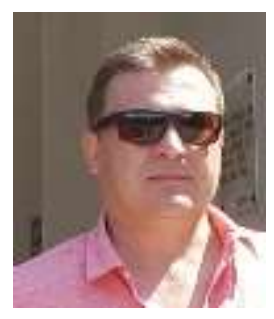

Marian STOICA received his degree on Informatics in Economy from the Bucharest University of Economic Studies in 1997 and his doctoral degree in economics in 2002. Since 1998 he is teaching in Bucharest University of Economic Studies, at Informatics and Cybernetics Economy Department. His research activity, started in 1996 and includes many themes, focused on management information systems, computer programming and information society. The main domains of research activity are Information Society, EActivities, Tele-Working, and Computer Science. The finality of research activity still today is represented by over 80 articles published, 25 books and over 40 scientific papers presented at national and international conferences. Since 1998, he is member of the research teams in over 30 research contracts with Romanian National Education Ministry and project manager in 5 national research projects.

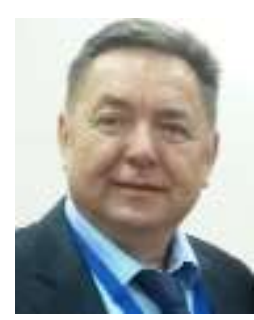

Bogdan GHILIC-MICU received his degree on Informatics in Economy from the Academy of Economic Studies Bucharest in 1984 and his doctoral degree in economics in 1996. Between 1984 and 1990 he worked in Computer Technology Institute from Bucharest as a researcher. Since 1990 he teaches in Academy of Economic Studies from Bucharest, at Informatics in Economy Department. His research activity, started in 1984 includes many themes, like computers programming, software integration and hardware testing. The main domain of his last research activity is the new economy - digital economy in information and knowledge society. Since 1998 he managed over 25 research projects like System methodology of distance learning and permanent education, The change and modernize of the economy and society in Romania, E-Romania - an information society for all, Social and environmental impact of new forms of work and activities in information society.

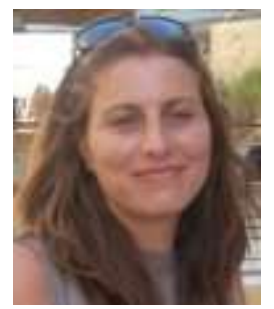

Marinela MIRCEA received her degree on Informatics in Economy from the Academy of Economic Studies, Bucharest in 2003 and his doctoral degree in economics in 2009. Since 2003 she is teaching in Academy of Economic Studies from Bucharest, at Informatics and Cybernetics Economy Department. Her work focuses on the programming, information system, business management and Business Intelligence. She published over 40 articles in journals and magazines in computer science, informatics and business management fields, over 30 papers presented at national and international conferences, symposiums and workshops, she was member over 15 research projects and project manager in 2 national research projects. She is the author and co-author of 12 books. In February 2009, she finished the doctoral stage, and her PhD thesis has the title Business management in digital economy. 


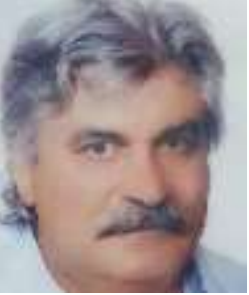

Panagiotis SINIOROS is Professor (Associate) $\mathrm{PhD}$. at University of West Attica, Athens (TEIATH), Greece, Department of Electrical Engineering. He graduated from the University of Turin, which offers a wide range of study options and boasts a remarkable research tradition. He has also published a number of articles in specialized journals and presented numerous papers at prestigious international conferences. 